THE NATURAL HISTORY OF TEFLON CATHETER ASSOCIATED PHLEBITIS (PHL) IN CHILDREN, Jeffery S. Garland,

500 David B. Nelson (Spon. by Michael J. Chusid). Medical College of Wisconsin, Children's Hospital of Wisconsin, Department of Pediatrics, Milwaukee, WI.

The purpose of this study was to examine the natural history of PHL during peripheral intravenous therapy with Teflon catheters ( $\mathrm{TC}$ ). Sites (286) were selected randomly and inspected daily for signs of PHL. Sites that developed PHL were followed until symptoms resolved. A random sample of TC tips were cultured.

Ten percent $(30 / 286)$ of the sites developed PHL. TC induced sepsis did not occur and colonization was not associated with PHL. Factors associated with an increased risk of PHL were: nafcillin ( $p<.001)$, aminoglycosides ( $p<.01)$, parenteral nutrition ( $P N)$ ( $p<.009$ ), age (older>younger, $p<.008)$, race (white>black, $p<.01$ ) and cannulation time ( $>72$ hours, $p<.01)$. Multiple linear regression analysis using these variables revealed PN, nafcillin, aminoglycoside therapy and age as the most important deteminants of the PHL rate. The mean onset and resolution time of PHL episodes was $69.2 \pm 39.3$ hours (range 200 hours) and $39.5+26.8$ hours (range 84 hours) respectively. In 9 cases, PHL was not fully developed until after the TC were removed. No factors hastened the onset of PHL and only PN prolonged the resolution time of PHL episodes. We conclude that the rate of PHL in children is less than that of recently published adult rates $(18-23 \%)$. Phlebitis appears to be a minor complication during infusion therapy with TC.

RACIAL AND ETHNIC DISTRIBUTION OF LEAD AND EP LEVELS IN THREE MASSACHUSETTS COMMUNITIES. John W. Graef,

501 Katherine Halvorsen, Yona Amitai, and Margaret Pfitzer the Division of Clinical Pharmacology and Toxicology, and the Developmental Evaluation Clinic, Boston, MA.

The Cooperative Lead Survey obtained venous blood samples from 615 pre-school ch1ldren ( 6 mos-6yrs) by door-to-door screening. Samples were assayed for lead by atomic absorption spectrophotometry, for erythrocyte protoprophyrin (EP) by hematofluorometry, for ferritin by radioimmunoassay and hbg, hct, and erythrocyte indices were determined by Coulter counter. A questionnafre was administered to all participating families in which, among other questions, they were asked to identify their racial identity (black, white, Asian, other) and their ethnic identity (Hispanic, Cambodian, Laotian, Vietnamese, Portuguese, other). Results wer as follows: mean lead level for the entire group was 12.19 $\pm 6.2 \mathrm{mcg} / \mathrm{dl}$ whole blood. H1ghest mean lead values and Laotians in particular $(14.20 \pm 4.8 \mathrm{mcg} / \mathrm{dl} ; \mathrm{n}=40)$. Although the mean blood level for blacks ( $13.04 \pm 8.3 \mathrm{mcg} / \mathrm{d} 1$ whole blood, $\mathrm{n}=54)$ was higher than for whites $(11.6 \pm 6.7 \mathrm{mcg} / \mathrm{d} 1$ whole blood, $\mathrm{n}=306$, the difference was not significant at the $p \leqslant .05$ level. $581 \mathrm{EP}$ values could be corrected for hematocrit to yield EP per deciliter of erythrocytes. $\mathrm{EP}_{\mathrm{RBC}}$ mean $\mathrm{EP}_{\mathrm{RBC}}$ for the entire group was $75.17 \pm 48.7 \mathrm{mcg} / \mathrm{dl} \mathrm{RBC}$. Highest mean $E P R B C$ values were again seen in Asians $(83.25 \pm 51.8 \mathrm{mcg} / \mathrm{dl} \mathrm{RBC}, \mathrm{n}=164)$ and again seen in Astans $(83.25 \pm 51.8 \mathrm{mcg} / \mathrm{dl}$ RBC
Laotians $(86.39 \pm 32.3 \mathrm{mcg} / \mathrm{d} 1 \mathrm{RBC}, \mathrm{n}=40)$.

We conclude that Southeast Asians particularly new immigrants, are at significant risk for increased lead levels.

\section{EXPO 86 - THE EFFECT ON A PEDIATRIC}

\section{2} EMERGENCY DEPARTMEN Lois J. Hlady, Andrew J. McNab, David F. Smith,
David F. Wensley (Spon. by Judith G. Hail)

The 1986 World's Exposition in Vancouver with over 22 million visits had a significant impact on the Emergency Department of the local pediatric fac1lity, B. C's Children's Hospital. A total of 559 children visited Emergency as a result of the fair366 In town for Expo and 193 who developed problems at the site, accounting for a $6 \%$ increase in emergency visits.

Fifty percent of visits were trauma related compared to yearly average of $25 \%$, while $62 \%$ of patients arriving from the site suffered trauma, mainly of a minor nature. These 119 site injuries included contusions (30), lacerations (25), and site injuries included contusions ( 30$)$, lacerations $(25)$, and
head injuries (22). The most common medical problems overall head injuries (22). The most common medical problems overall
were viral 1llnesses (64), otitis media (63), gastroenteritis (35) and asthma (26).

The average age was 6.99 years. An increased number (36\%) arrived on weekends and holldays. While most Canadians have medical coverage, one hundred and seventy six patients were not insured. An additional strain was placed on laboratory factlities and pharmacy, 242 prescriptions were given. There factlities and pharmacy, 242 prescriptions were given. There
were 24 hospltal admissions; one pediatric death at the site did not reach our factlity.

These findings are of importance for cities planning similar events in future.
COMPUTER ASSISTED MANAGEMENT AND REVIEW OF CHILD ABUSE CASES IN THE SOUTH BRONX. Philip I. Hubel

503 (Spon. by Lawrence R. Shapiro). New York Medical College, Lincoln Hospital, Department of Pediatrics, Bronx, N.Y.

A microcomputer data base munagement system was used for weekly review of all 675 children admitted to the Lincoln Hospital Pediatric Emergency Room (PER) during a one year period $(10 / 21 / 85-10 / 20 / 86)$ reported to the state child protective services agency. The time period corresponds with the initiation of a Joint Response (JR) protocol in New York City Health And Hospital Corporation hospitals created to involve both police and child protective services in cases of severe child abuse (CA) and child sexual abuse (SA). The computerized data assisted the interagency transfer of information, indicating where information was lacking.

of all cases, $251 / 675(37 \%)$ were SA related, $63 / 251$ (25\%) male, average age 7.2 years, and $188 / 251(75 \%)$ female, average age 8.8 years. The age range of SA cases was from 7 weeks to 18 years. A "rule-out" diagnosis was used in $97 / 251$ (39\%) SA cases. 114/675 (17\%) were JR cases. Of these, $72 / 114$ (63\%) were SA related. $127 / 675$ (19\%) of all cases were brought to the PER by child protective services workers for examination after a CA diagnosis had been made.

The majority of cases ( $56 \%$ ) were brought to the PER during the evening shift ( 4 P.M. to 12 midnight). Although the daily average is less than two cases per day, up to nine abuse cases were seen during a twenty-four hour period. Forty-two percent of cases were seen during the four warm months of May, June, July and August.

DIAGNOSIS AND CONTROL OF NOSOCOMIAL RESPIRATORY SYNCYTIAL VIRUS (RSV) INFECTIONS IN A PEDIATRIC

504 HOSPITAL. Clark B. Inderlied, Mary E. Lemmelin, Keiko J. Oda, Teresa M. Courville and Harry T. Kright. University of Southern California School of Medicine, Childrens Hospital, Department of Pathology and Pediatrics, Los Angeles.

RSV is a major cause of bronchiolitis in children less than $2 y$ and is an important cause of nosocomial infections especially in acutely ill neonates. During the 1985-86 RSV season over 245 specimens, mostly NP wash and ET aspirates, were cultured in Hep- 2 cells and assayed with a fluorescent antibody (DFA). At the peak, 708 of specimens were positive indicating that the infections were epidemic. The DAF was more sensitive; 158 of specimens were positive by DFA only. Based on a 3-7 day incubation, lab tests and clinical status 18 infections were tory infections. Of the 18 patients, 10 had underlying cardiac or pulmonary disease. Cohorting and contact isolation was instituted and gown, mask and gloves were used in the NICU. There were no further nosocomial infections although $50 \mathrm{z}$ of specimens submitted to the lab were positive for RSV. DFA and culture results were correlated with chest $x$-ray and symptoms. In summary, the DFA is a useful adjunct to the clinical diagnosis of RSV. Culture is unnecessary. Cohorting and contact isolation are sufficient except perhaps with the highest risk patients for effective infection control.

ARENTAL SMOKING CESSATION COUNSELING BY PEDIATRIC RESIDENTS. Thomas G. Irons, Suzanne $T$. White

505 Richard D. Kenney (Spon. by James P. Gutai), Members of the UNC Faculty Development Program, University

The adverse effects of parental smoking on children are widely recognized, yet little is known about how of ten and how pediatricians counsel patients' parents to stop smoking. We, therefore, surveyed 80 pediatric residents from four North Carolina training programs to determine self-reported practice of parental smoking cessation counseling. The response rate was
$85 \%(67 / 80)$.

Aithough $84 \%$ of the responding residents agreed that pediatricians should try to convince parents to stop smoking, residents reported infrequently counseling parents to do so. On average, residents asked $35 \%$ of new patients 'parents and $26 \%$ of return patients parents to stop smoking. In those who were counseled, counseling was brief; mean duration was 2.8 were counseled, counseling was brief; mean duration was 2.8
minutes. Very few residents used specific counseling techniques to help parents quit: only $8 \%$ often or always assessed motivation to quit, $5 \%$ advised the parents to set a quit date, $3 \%$ discussed obstacles to quitting, $2 \%$ gave the parent self-help written materials, and none prescribed nicotine gum or scheduled follow-up to monitor progress. A third of residents (35\%) did not feel confident in their ability to counsel, half $(51 \%)$ felt ill-prepared to counsel, and most (91\%) felt their counseling was unsuccessfur.

Despite positive attitudes about trying to convince patients parents to stop smoking, pediatric residents seldom counsel parents and even less often use effective counseling techniques. 